\title{
SUSTAINABLE POST-DISASTER SETTLEMENT (SPS) ASSESSMENT MODEL FOR EVALUATING PERFORMANCE OF CONSTRUCTION MANAGEMENT IN POST-FLOOD RISK-REDUCTION AND RECOVERY
}

\author{
ALI KEYVANFAR ${ }^{1,2}$, AREZOU SHAFAGHAT ${ }^{2,3 *}$, NURULFARA YA'ACOB ${ }^{4}$ AND AMILIA \\ ROSLAN $^{4}$ \\ ${ }^{1}$ College of Architecture and Construction Management, Kennesaw State University, Marietta, Georgia 30060, USA. \\ ${ }^{2}$ CIFAL Atlanta, United Nations Institute for Training and Research (UNITAR), Kennesaw, Georgia 30144, USA. ${ }^{3}$ Institute \\ of Research and Development, Duy Tan University, Da Nang 550000, Vietnam. ${ }^{4}$ Faculty of Civil Engineering, Universiti \\ Teknologi Malaysia, Skudai 81310, Malaysia.
}

*Corresponding author: Dr. Arezou Shafaghat (arezou@utm.my)

Submitted final draft: 12 July $2020 \quad$ Accepted: 27 August $2020 \quad$ http://doi.org/10.46754/jssm.2021.07.013

\begin{abstract}
Understanding post-flood risks and construction management capacities can help us handle disasters effectively and appropriately. The construction professionals need a post-disaster assessment model capable of evaluating construction management performances and capabilities from social, economic, and technical aspects. This research developed a universal decision support tool called Sustainable Post-disaster Settlement (SPS) assessment model. The research has two objectives. Objective one is to investigate and identify the performance indicators of construction management for post-flood risk reduction and recovery, which were classified to sustainability bottom-line clusters (social, economic, and technology), and three sub-clusters (cost, quality, and time) by applying critical literature review method. The research identified 42 indicators and revealed that $\mathrm{SQ}_{2}$. Layout Requirement and $\mathrm{SQ}_{1}$. Flexible design should be extensively considered in post-flood disaster settlement. Objective two was to measure the weights of indicators by employing the content analysis and rescaling normalization methods. It found that the social cluster $\left(\mathrm{AX}_{\mathrm{S}} \mathrm{Sum}=2.298\right)$ is more critical than finance and technology clusters in post-flood disaster settlement. Having the weights of indicators, the SPS assessment model was formulated, which was validated by using the Weighted Sum Method. The validation study determined that the SPS model is practically usable for performance evaluation of construction management projects.
\end{abstract}

Keywords: Sustainable construction management, post-disaster settlement, flood disaster management.

\section{Introduction}

Disaster is a set of failures that overwhelms the capability of a community to respond without external help when these three continuums intersect in space and time (Okada et al., 2014); people, society (i.e., a set of habitats, livelihoods, and social constructs), and complex events (e.g., floods, earthquakes). Single or multiple natural hazards cause disasters, which may extremely affect morbidity, homelessness, joblessness, economic losses, or environmental changes (Okada et al., 2014). Natural disasters are frequently happening all around the world, which cause loss of properties and people's lives. Among natural types of disasters, landslides and floods are the most destructive that occur regularly (United Nations, 2012). High potential loss exposures of flooded cities and villages are; people, property, infrastructure, business enterprise, government centers, crops wildlife, and natural resources (Ghamghami and Irannejad, 2019; Mohh et al., 2019). The key drivers of flood disasters in urban and suburban areas are extreme rainfalls, nutrient and pollutant loading, rapid urbanization, climate change, and socio-economic trends (De Bruijn, 2004; Shafaghat et al., 2016a, Shafaghat et al., 2016b). Human activities trigger flooding disasters substantially; mainly through resurfacing of roads, deforestation, drainage system failure, land-use changes, and topography changes (De 
Bruijn, 2004). Figure 1 shows the potential risk of urban flooding in countries around the world. As can be seen, most of the countries have the potential of flooding. China, Japan, Sri Lanka, India, Pakistan, Indonesia, Malaysia, and Haiti had disastrous floods over the past two decades, causing billions in damage. Therefore, flood disaster settlement has become a frontier agenda for governments, engineers and developers of many nations in the world.

The ever-growing global population, demographic shifts, climate change, and increasing pressure on limited natural resources have all brought disaster management to the top of government policies. Disaster management and disaster settlement address the significant challenge of tremendous opportunities to promote traditional techniques and technologies of building design and construction management (Surwase et al., 2019). The building and construction industry has realized that disaster settlements should fulfill users' requirements while ensuring quality performance of the project life-cycle through a sustainable design and construction approach (Shafaghat et al., 2014; Ubaura et al., 2016; Keyvanfar et al., 2018). The construction industry has aimed to move toward projects that can build, operate and renovate more efficient and affordable houses, and simultaneously meet users' needs and requirements more effectively. Therefore, it is essential to promote and upgrade the performance of construction management for the community and society who are directly exposed to natural hazards (De Bruijn, 2004; Gourbesville, 2012). Disaster management consists of a variety of actions and activities incorporated continuously, either sequential or parallel, in different degrees of emphasis (Atmanand, 2003). Accordingly, disaster management has two main phases; i) pre-disaster risk-reduction phase (includes activities such as preparedness, mitigation, and prevention), and ii) post-disaster recovery phase (includes activities of rehabilitation, recovery, and response) (Atmanand, 2003). On this basis, the researchers have initiated several disaster management theoretical frameworks, models, tools and guidelines.

Sementelli (2007) states that theorizing disaster management aims to understand the nature of either human-made or natural disasters. It persuades the authorities, scholars, practitioners and users to find answer to their rational and irrational questions on the disaster. As disaster affects numerous people, it needs special consideration through the lens of critical theory, post-modernism and resilience. There are several disaster theories and practices, from a simple approach to sophisticated tactics merging social, political,

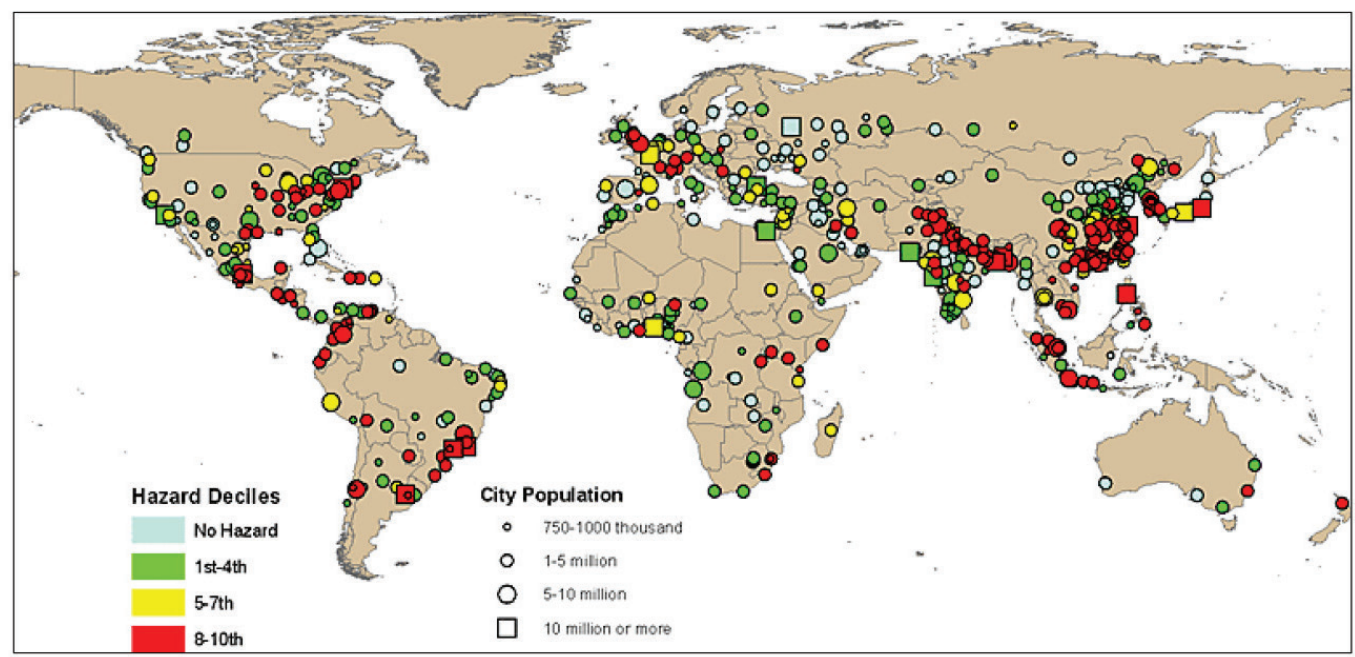

Figure 1: Global potential risk of flooding (in the country scale) (Source: United Nations, 2012) 
and economic aspects, meanwhile focusing on planning, response and preparation tasks (Gotham, 2007). These tasks have collaborated with management and mitigation, which is called disaster management and administration (Barnett et al., 2005; Sementelli, 2007). Disaster theories can be categorized into two dimensions (i.e., process and tools), and are clustered into four categories; i) decision-making or decision theories, ii) leadership and management theories (also called administrative theories), iii) social theories, and iv) economic theories (also called resource economic theories, or risk management theories) (Sementelli, 2007). The disaster theories cope with a series of stages, steps, procedures, heuristics and descriptions. ecision theory and administrative theory are the most common and most abundant categories, and current research has focused on them. Scholars have tried to promote disaster theories by combing the categories, integrating the complexity concept into categories, or even reframing disaster management into a new framework (such as sustainable management, vulnerability management, etc). The current research has applied decision theories and administrative theories to frame a post-disaster management model which integrates the information access theory (initiated by Annand and Forshner, 1995), and data quality theory (initiated by Geale, 2012).

The decision theories are valuable tools commonly used for understanding practical goals through a minimum process. These theories have mainly emerged from the fundamentals of decision making science, such as classic decision making (e.g., Allison, 1971; Cohen et al., 1972). Decision theories have a variety of applications in disaster and crisis management; such as, public health (Barnett et al., 2005), adaptation (Lin et al., 2006), data simulation (Geale, 2012), remote sensing, Geographic Information Systems (GIS) (Levy et al., 2005), and system theories (Coetzee and Van Niekerk, 2012). Notably, these varieties have claimed beyond the direct applications of concepts; for instance, risk perception (Barnett et al., 2005; Connor, 2006), and decision-making under uncertainty (Anand and Forshner, 1995). Recently, O'sullivan et al. (2013) have integrated complexity theory with decision theories and offered the reliance on classical and neo-classical approaches to decision-making in disaster management projects. On the other hand, the administrative theories have been developed based on the needs for long-term changes and leadership, as well as crisis leadership competencies (James and Wooten, 2005). Administrative theories have been used significantly for evaluating and predicting climatic disasters (such as typhoons). Sementelli (2007) and Fairholm (2004) state that administrative theories strongly need to be improved, being concurrently linked with organizational and leadership science. As the leadership studies cope with change, disaster conceptions have to be changed as well (O'sullivan et al., 2013). Guikema (2009) has merged the elements of learning theory, role theory, and decision theory in a leadership study and developed a model called readiness model. The model deals with the functions of training, knowledge, responsibilities and roles, which lead to consistent behaviors, coherent, and rehearsed at all levels of the organization. Moreover, the resilience theory is under administrative theories which treats the communities to have a flexible design of the information and resources (Godschalk, 2003; Norris et al., 2008). According to resilience theory, the cities should have the economic resources which can aid in reducing risks and social vulnerability (Norris et al., 2008; Longstaff, 2005).

Underpinning disaster theories, scholars have developed several disaster management models and tools. The major disaster management models comprise a series of activities, conditions, phases and resources, such as identifying resources, using resources, specifying actions and conditions. Incorporating these elements makes the disaster management models practical, effective and useful. For example, Ibrahim-Razi et al. (2003) model composes eight phases; inception of error; accumulation of errors; warning; failure of correction; disaster impending stages; triggering events; emergency stage, and settlement. 
Kelly (1998) states that disaster management models can be clustered into three categories; i) Integrated models, ii) Logical models, and iii) Causes models. The integrated models (or eventaction models) characterize the disaster phases by developing the functions, such as monitoring and strategic planning (e.g., Manitoba Integrated Model, and Weichselgartner Model) through four main components; hazard assessment, risk management, mitigation and preparedness. The logical models have simple disaster stages, and underline the basic actions towards disaster control and reduction (e.g., Expand and contract Model, Kimberly's Model, Tuscaloosa Model, Circular Model). The causes models suggest the underlying causes of disasters and do not deal with the disaster stages (e.g., Crunch Model, and Release Model). Collectively, the disaster management models are mostly for recovery or mitigation and evaluating the economic and social aspects. Weichselgartner's (2001) model conducts the assessment of possible damages (especially, assessment of vulnerability) and can reduce natural hazards and the potential damage. The Crunch model can identify the causes of a disaster, the progression of vulnerability, people's demands, and estimate the unsafe conditions and dynamic pressure (Heijmans, 2001; Marcus, 2005). Some disaster management models can obtain the risk profiles. For instance, Keller and Al-Madhari (1996) have developed a probabilistic model capable of predicting the disaster magnitude consequences and returns. While, some models (such as Pressure and Release models) function reversely (Marcus, 2005). These models apply the preventive and mitigation theories to reduce the risk of disasters and prepare the community to deal with emergencies.

In particular, a few disaster assessment models have been developed for evaluating the post-disasters. These models are such resilience system models, quantitative models, with post-disaster relief operation and humanitarian aid purposes based on OR/MS strategies (Operations Research/Management of Science strategies). Kou et al. (2014) state that most of the disaster assessment models have been developed based on multi-criteria decision making (MCDM) methods, expert systems, or integrated methods (combining survey questionnaire, MCDM methods, Delphi method, or fuzzy logic methods). Indeed, each disaster assessment model has specific scopes and series of limitations. For instance, Zhao et al. (2014) have developed a dynamic risk assessment model for flood disasters based on risk indices and projection pursuit theory. The model works from the full structure to detailed components. The model has employed the fuzzy analytic hierarchy method to determine the index weights, and the neural network algorithm to monitor the index system, as well as projection pursuit theory of clustering the spatial data. By confirming the risk level of the flood disaster, the model indicates the control strategies for local conditions. Arbon et al. (2012) have developed the community disaster resilience model, which comprises risk, vulnerability, available resources, relationships of community connectedness, planning and procedures. The community members can use this model to assess their disaster resilience, and plan for further resilience. The local government and emergency services can implement those plans for quality improvement. Tsai and Chen (2011) have developed a natural disaster risk assessment model, which is mainly used by the tourist industry and tourism asset owners. The model aids risk analysis mechanisms, specifically, for the management of tourist facilities and the centralization of people in times of danger. Tsai and Chen (2011) state that most of the existing disaster risk assessment models are very costly and timely, and are applicable for high-value facilities (such as industrial parks). Kimberly's (2003) model is a four-stage disaster assessment model that covers mitigation, preparation, response, and recovery phases, which focuses only on emergency management in hospitals. Vecere et al. (2017) have developed an emergency assessment model for major earthquake events that can evaluate the shelter needs of displaced people. The model functions based on different scales of disaster (e.g., shortterm actions for temporary housing and public 
sheltering and better local conditions). The model is useful and instrumental, especially for local governments.

However, disaster management models have several shortcomings and limitations, commonly in standardized, replicable, independent and systematic approaches. isaster management models formerly used subjective or quantitative data. In contrast, advanced models use qualitative, systematic and objective data (capturing through satellite imagery, geocoded photographs, internet-based statistics, field surveys, etc.). Vecere et al. (2017) state that disaster assessment models need substantial improvement in the future. For example, ERGO-EQ and HAZUS-MH are the most wellestablished disaster management software. Still, the main shortcoming of such software is to consider all indicators involved in the shelter needs estimation (Vecere et al., 2017). It could be understood that there is a gap in postdisaster assessment models that could measure the performance of sustainable construction management key-drivers. Kelly (1998) states that developing the post-disaster assessment model is very useful because the disaster assessment model underpins theories. Therefore it can compare the actual conditions, which helps better understand the current situation and facilitate disaster management plans and processes. Also, the disaster assessment model can handle complexities while distinguishing the critical elements and has particular capacities in responding to severe time constraints (Kelly, 1998). Furthermore, he states that the disaster assessment model should be primarily available for quantifying and measuring accurately and comprehensively the disaster events. The documented disaster management model can produce a standard, understandable basis for all involved, likewise, it can establish a perfect integration of relief and recovery efforts (Kelly, 1998). Cumulatively, Asghar et al. (2006) state that the disaster management models have the following limitations;

- Most of the models were designed to resolve disasters based on only four phases; mitigation, prevention, response, and recovery.

- One comprehensive model does not exist, which is capable of conducting almost all of the significant activities, stages, and phases in disaster management through a logical sequence.

- The models do not ponder environmental conditions as a sensible element to the severity of a disaster.

To bridge the above-mentioned gaps, the current research aims to develop a novel universal post-disaster assessment model capable of evaluating the performance of construction management in flood riskreduction from sustainability point of view, called Sustainable Post-disaster Settlement (SPS) Assessment Model. To achieve the aim, the research has articulated two objectives based on decision theories and administrative theories. Objective one is to identify the performance indicators of construction management for postflood risk reduction and recovery after. The research will review the literature on disaster management underpinning the decision-making theories and administrative theories and using the Critical Literature Review (CLR) method. Then the research will cluster the performance indicators based on sustainability dimensions (i.e., social, economic, and technology) and construction management golden triangle (i.e., cost, quality, and time). Section three presents the CLR procedure and outcome in detail. Objective two is to measure the weights of all indicators using Content Analysis (CA) method and unity-based normalization methods. The SPS assessment model will formulate the index based on these weight values. Section three elaborates on the procedures and findings of the CA and normalization. Accordingly, the research has articulated three research questions. What are key performance indicators of construction management for post-flood risk reduction and recovery? How much each indicator can contribute to the overall postflood disaster settlement? And, how successful 
is a construction management project 1 in postflood disaster settlement? Having the answers to these questions, the research will formulate the SPS assessment model, and then, the model will be validated through an expert-input study applying the Weighted Sum Method (WSM). Notably, the research flowchart was designed based on the waterfall process method. The waterfall process is the most established and simple method for index model development (Borecký et al., 2016). The waterfall process has a series of fundamental steps; model conceptualization, model design and analysis, and model testing. Accordingly, the research has followed the waterfall procedure (i.e., indicators investigation and identification, index model formulation, and index model validation), which are presented respectively.

\section{Materials and Methods}

\section{Critical Literature Review (CLR)}

To fulfill the first objective of this study, the researchers investigated the construction management drivers for post-disaster settlement after floods by employing a critical literature review (CLR) method. Mingers (2003) states that vital literature review has four aspects of criticism; critique of rhetoric, the critique of tradition, the critique of authority, and the critique of objectivity. The CLR method has an upward spiral review process, starting with defining the keywords and research objectives (Saunders and Rojon, 2011), which can lead to an accurate list of drivers. Thus, this research has applied the following keywords (either in a single of combination forms) to obtain the initial list of references; flood, post-disaster settlement, disaster theories, construction management, disaster management, and disaster modeling. The references were studied critically and evaluated for the potential ideas, and then the literature review was written for the first draft. Next, the keywords were redefined to undertake further searches while sticking to the research objectives. According to Mingers (2003), this stage can be replayed as long as the researcher's thought is matured, and searching outcome is focused very precisely. The current research has conducted several literature screenings and narrowing them down to the most scientific databases; mainly, the International Journal of Disaster Resilience in the Built Environment, International Planning Studies, Disaster Prevention and Management, International Journal of Project Management, and Journal of Civil Engineering and Architecture. The screened literature was studied critically through summarizing, comparing, and different techniques to achieve the key drivers of construction management for post-flood disaster settlement. Besides, the CLR method has two approaches; deductive and inductive (Saunders and Rojon, 2011), which the current research has followed the deductive approach aided in designing the theoretical and conceptual frameworks based on the tested data. The outcome of the critical literature review was analyzed through the content analysis to understand the degree of citation of each indicator.

\section{Content Analysis (CA)}

By completing the CLR process, the research would identify the list of indicators. The Content Analysis (CA) method is a useful method to identify the quality of quantity and most-encoded indicators (Mayring, 2003). The CA method determines the frequency (i.e., depth of citation) of each indicator, which will be calibrated later through the normalization process. It is essential to interpret the quantitative results (i.e., depth of citation) of the content analysis. This research has conducted the following content analysis process instructed by Mayring (2003); i) Material selection (it has been conducted through critical literature review), ii) Descriptive analysis to assess the formal aspects of the materials (here, the number of citations to each indicator), iii) Category selection to define the structural dimensions and categories of the major topics of analysis (here, categorizing the criteria and sub-criteria), and iv) Material evaluation (here, to analyze and sort the citation data according to the structural clusters; social, economic, and technology). After completing 
the content analysis, the research has conducted the normalization to determine the actual weights of all indicators, which were used in developing the SPS assessment model.

\section{Normalization}

Normalization is a technique to make a normal distribution of data. The normalization aims to remove systematic technical effects that occur in the data analysis and to ensure technical bias has minimal impact on the results (Robinson\& Oshlack, 2010; Batista \& Monard, 2003;). This research has conducted the normalization to enable us to compare the content analysis outcome accurately and efficiently. This study has applied the rescaling normalization method, which rescales data values between 0 and 1 . It is also usually called feature scaling or unity-based normalization (Robinson and Oshlack, 2010) (see Equation 1), where $X_{n}$ is the normalized value. The scaling normalization method adjusts the values of different scales (here, depth of citation-DoC) to a standard scale.

$$
X_{n}=\frac{X-X_{\min }}{X_{\max }-X_{\min }} \quad \text { (Equation 1) }
$$

By completing the normalization process, the weight of each indicator will be determined, which will then be transferred directly to the SPS index.

\section{Weighted Sum Method (WSM)}

For model validation, the research has conducted an expert-input study using the Weighted Sum method (WSM). The team of experts was involved in the expert-input study as the endusers of the SPS assessment model. WSM is an optimization method making an alternative selection (Wang et al., 2016). WSM can convert a multi-objective to a single-objective (Marler et al., 2010; Lamit et al., 2013). Liu and Li (2009) state that WSM can "scale the set of objectives into a single objective by multiplying each objective with a user-supplied weight, and finally provides the equal weight of decisionmakers." WSM produces a decision matrix based on the usability factors in a 5-point scale (where one (1) refers to poor to five (5) refers to very good) (see Equations 2 and 3). Equation 3 indicates the consensus value. If the indicator receives equal or more than $70 \%$ consensus, the validity of the indicator will be approved.

$$
W S M\left(a_{i}\right)=\left(\sum_{j=1}^{n} \quad w_{j}\right) \times a_{i} \quad(\text { Equation 2) }
$$

where,

' $W_{i}$ ', is the given weight by the expert involved in the expert-input study for indicator ' $j$ '

' $a$ ', is the under-discussion indicator

$W S M\left(a_{i}\right) / W S M(a)_{\max } \times 100=$ Consensus\% (Equation 3) where,

$\operatorname{WSM}(a)_{\max }$, is the maximum possible weight of the under-discussion indicator ' $a_{i}$ '

\section{Analysis and Findings}

\section{Construction Management Indicators of Post-disaster Settlement}

Post-disaster settlement is a dynamic process for replacing lost housing stock, returning buildings to pre-disaster state, returning to economic function, preserving buildings, and reducing vulnerability (Brown et al., 2008; Comerio, 2004). Rubin (1985) states that the quality and speed of the disaster settlement process are fundamentals. The measurement of successful settlement and recovery depends on; i) timeframe, ii) scale, and iii) perceptions (Rubin, 1985; Tyler et al., 2002). The timeframe factor extends to "the fate of the individual households or businesses which may not be determined until several years after the disaster." The scale factor extends to different levels of damage, which should be analyzed collectively (in individual, household, business, community, or neighborhood scales). The perception factor extends to the perspective of the evaluators (i.e., independent, local, province, state departments, funding recipient, or funding provider). From the cost point of view, the construction of post-disaster settlement needs less duration, so less management costs than conventional construction. In contrast, minimum skilledworkers and the minimum trading cost are required. Moreover, the construction managers 
should provide the highest quality output by either skilled and unskilled workers. Besides, the post-disaster construction projects should take less time than typical types through reducing the activities and working hour supervision. Applying the CLR method, the study has investigated 42 construction management indicators. The indicators have been clustered based on the construction management golden triangle (i.e., time, quality, and cost), meanwhile were clustered based on the sustainability triple-bottom lines (i.e., social, economic, and technology). These classifications are supported by the disaster theories as well. Tables 1, 2, 3 present the indicators, the definitions, and citations of each sustainability cluster, separately.

\section{Developing the SPS Assessment Model}

To fulfill the second objective, the content analysis method was applied to measure the weight (i.e., Depth of Citation (DoC)) of each indicator (see Table 4). According to Figure 2, the indicator $\mathrm{SQ}_{2}$ Layout Requirement has been mostly referred to in previous studies $(\mathrm{DoC}=$ 13), which is followed by $\mathrm{SQ}_{1}$ Flexible Design $($ DoC $=11)$; hence, these indicators should be extensively considered in post-disaster construction management. Besides, Figure 2 indicates the following indicators play significant roles in post-disaster settlement $(\mathrm{DoC}=8) ; \mathrm{SQ}_{5}$ Available Resources, $\mathrm{SQ}_{6}$ Re-constructability / Maintainability/ Reconstruction, EC 1 Less transaction with a supplier, $\mathrm{ET}_{3}$ Accessibility to Local Resource, $\mathrm{TC}_{2}$ Less Life Cycle cost, $\mathrm{TQ}_{3}$ Availability, and $\mathrm{TQ}_{9}$ Material Handling. In contrast, the indicator $\mathrm{EQ}_{2}$ Low cost of Quality for Maintenance, has received the lowest result $(\mathrm{DoC}=2)$, which shows its minor contribution to the post-disaster settlement.

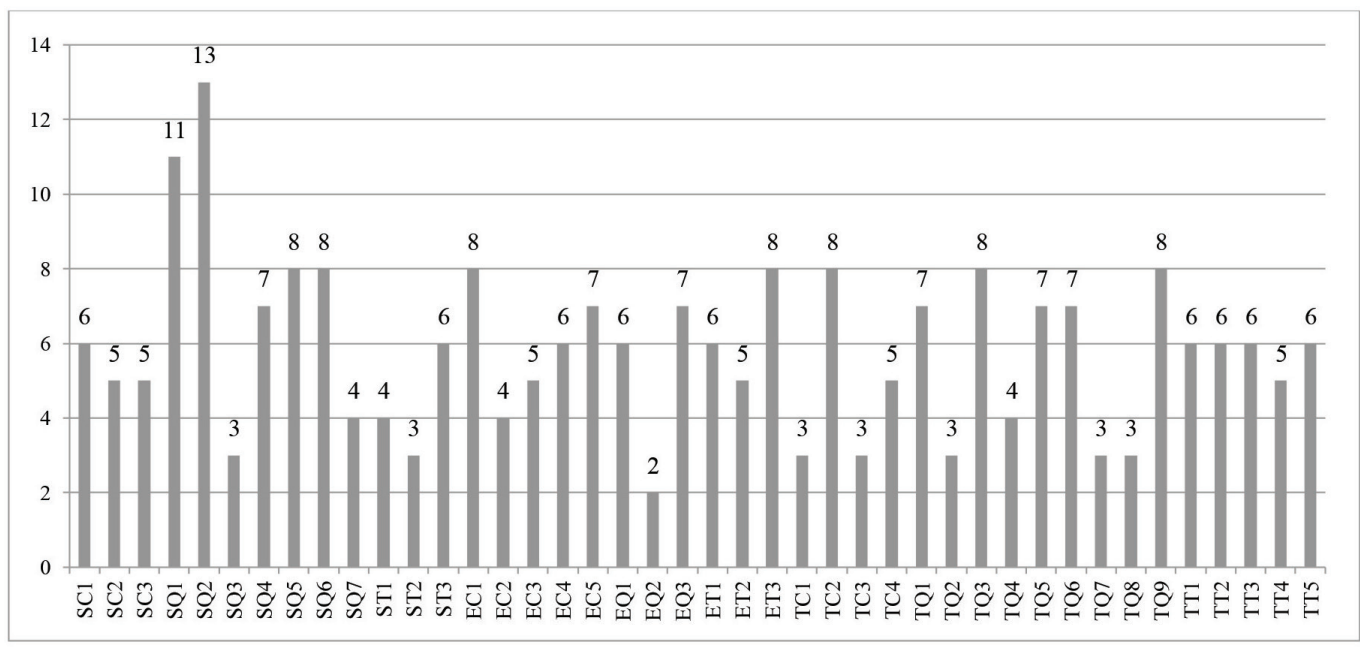

Figure 2: Depth of citation of construction management indicators of post-disaster settlement 


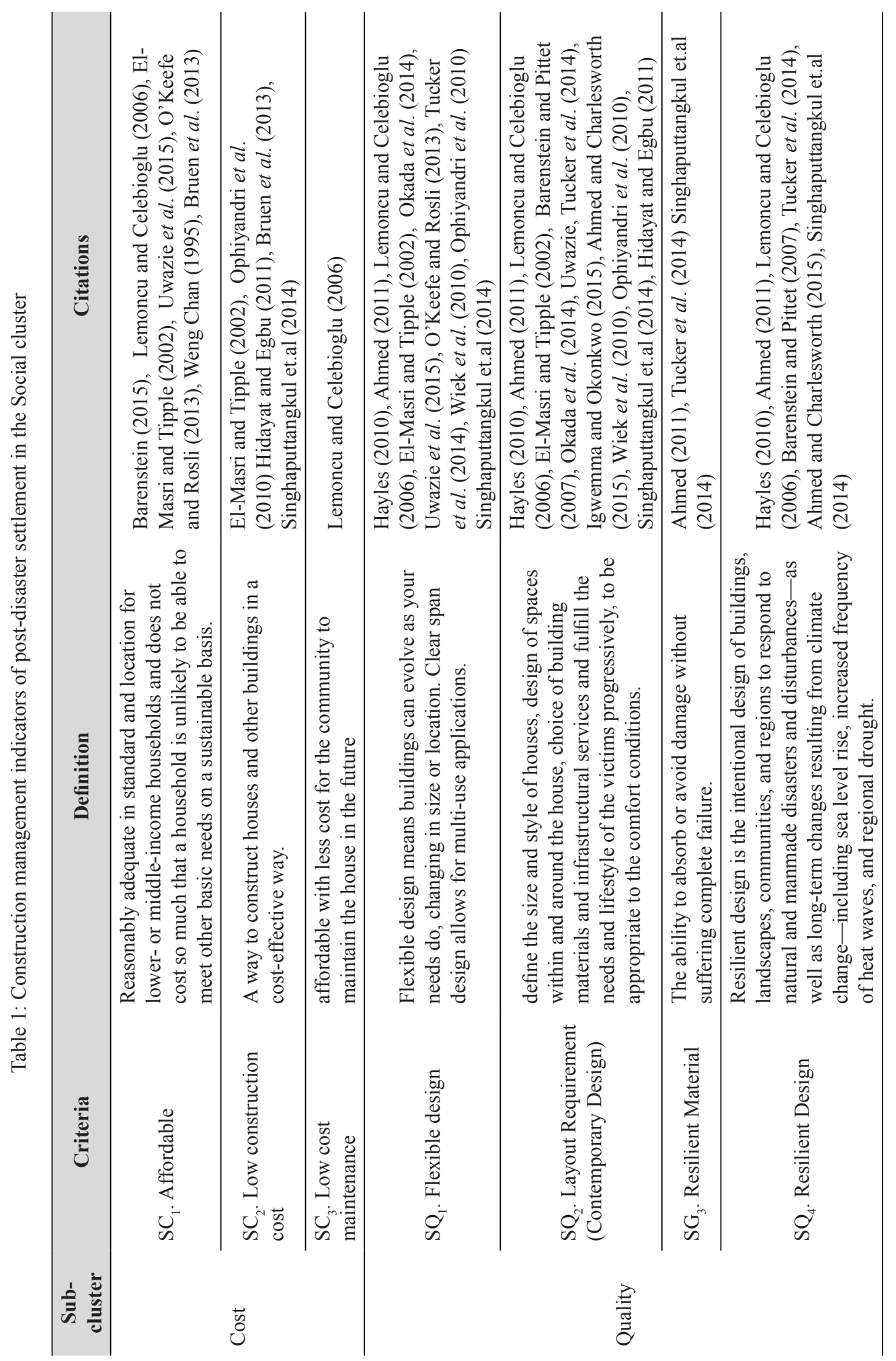




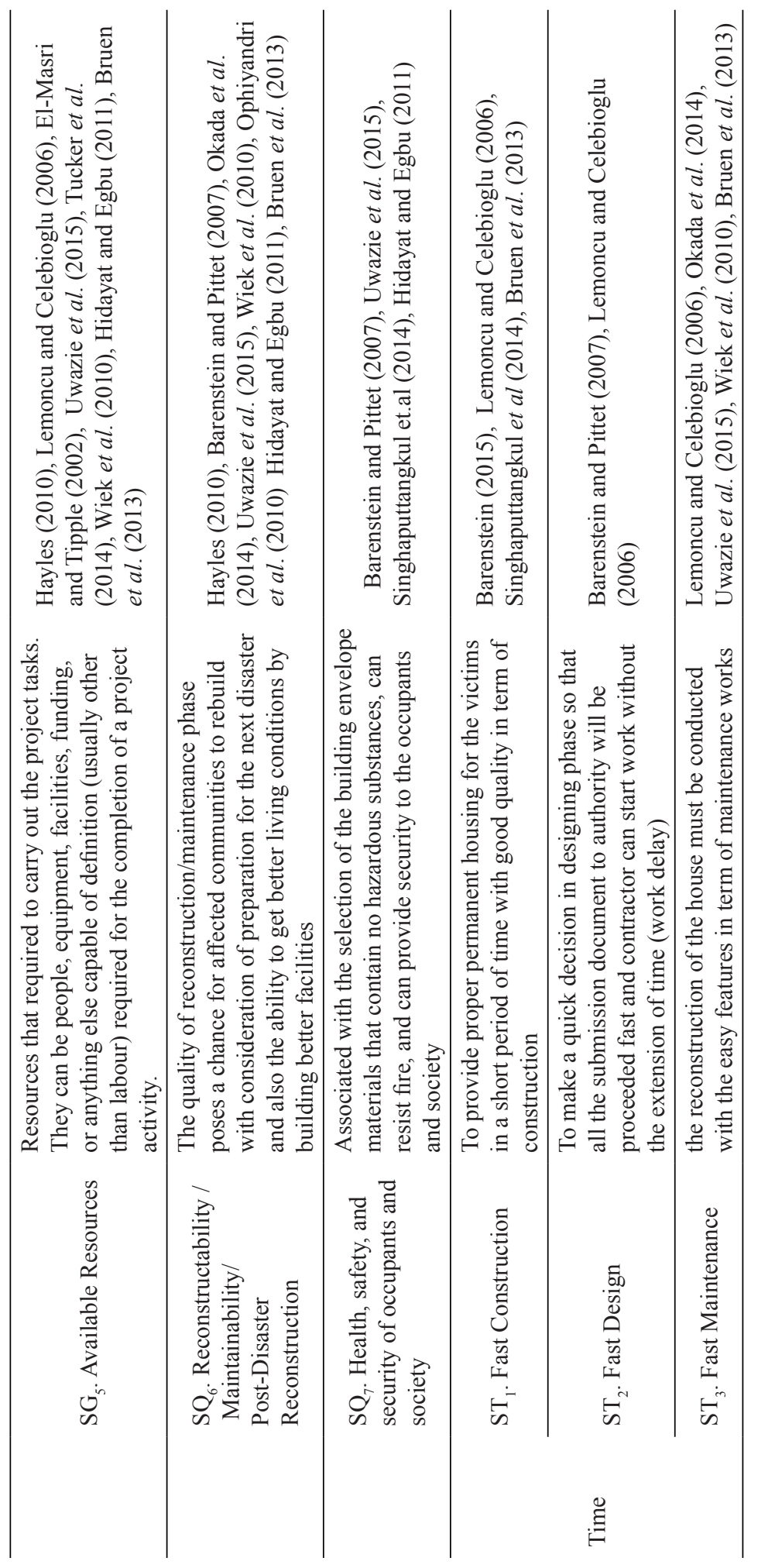




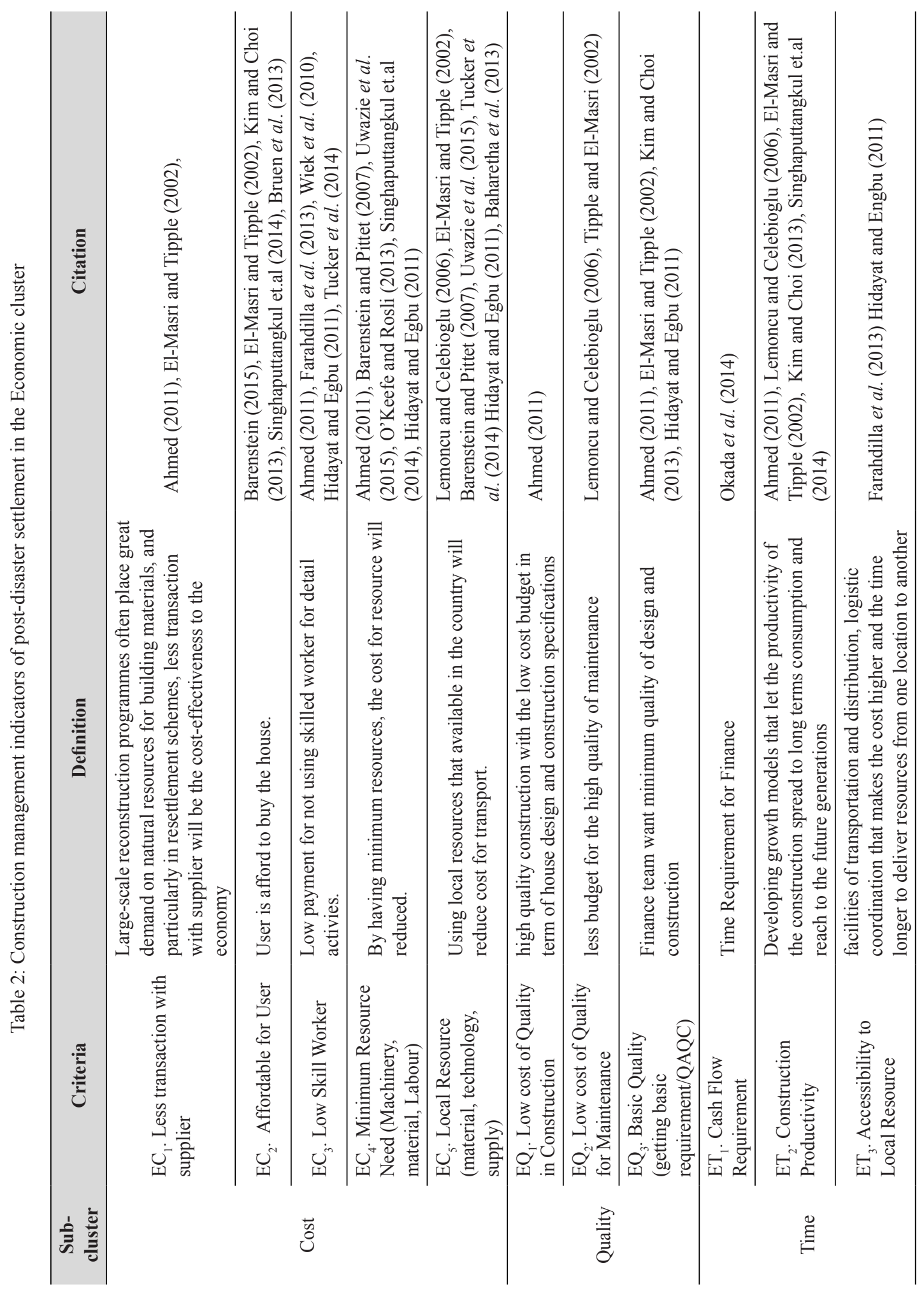




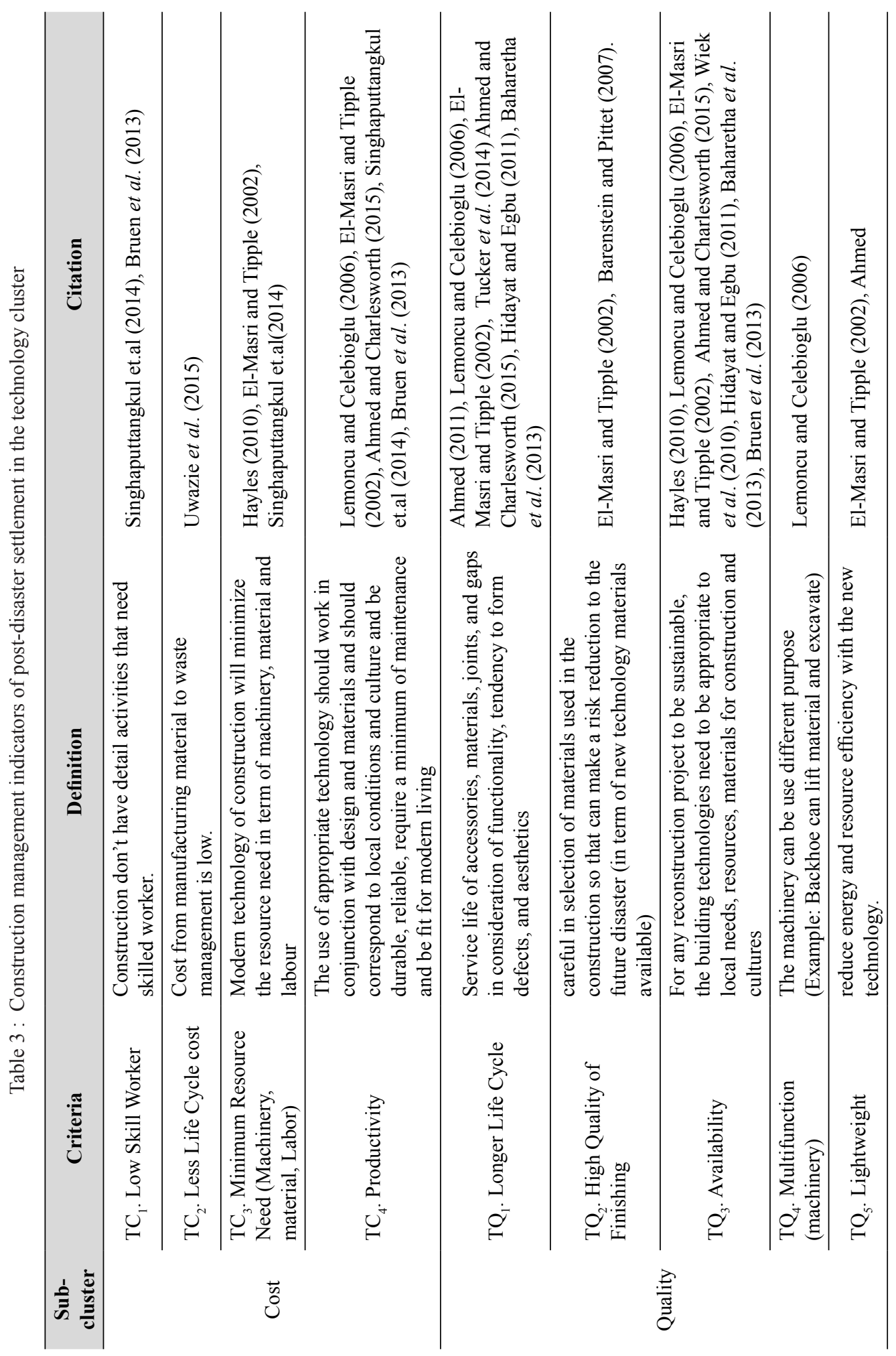




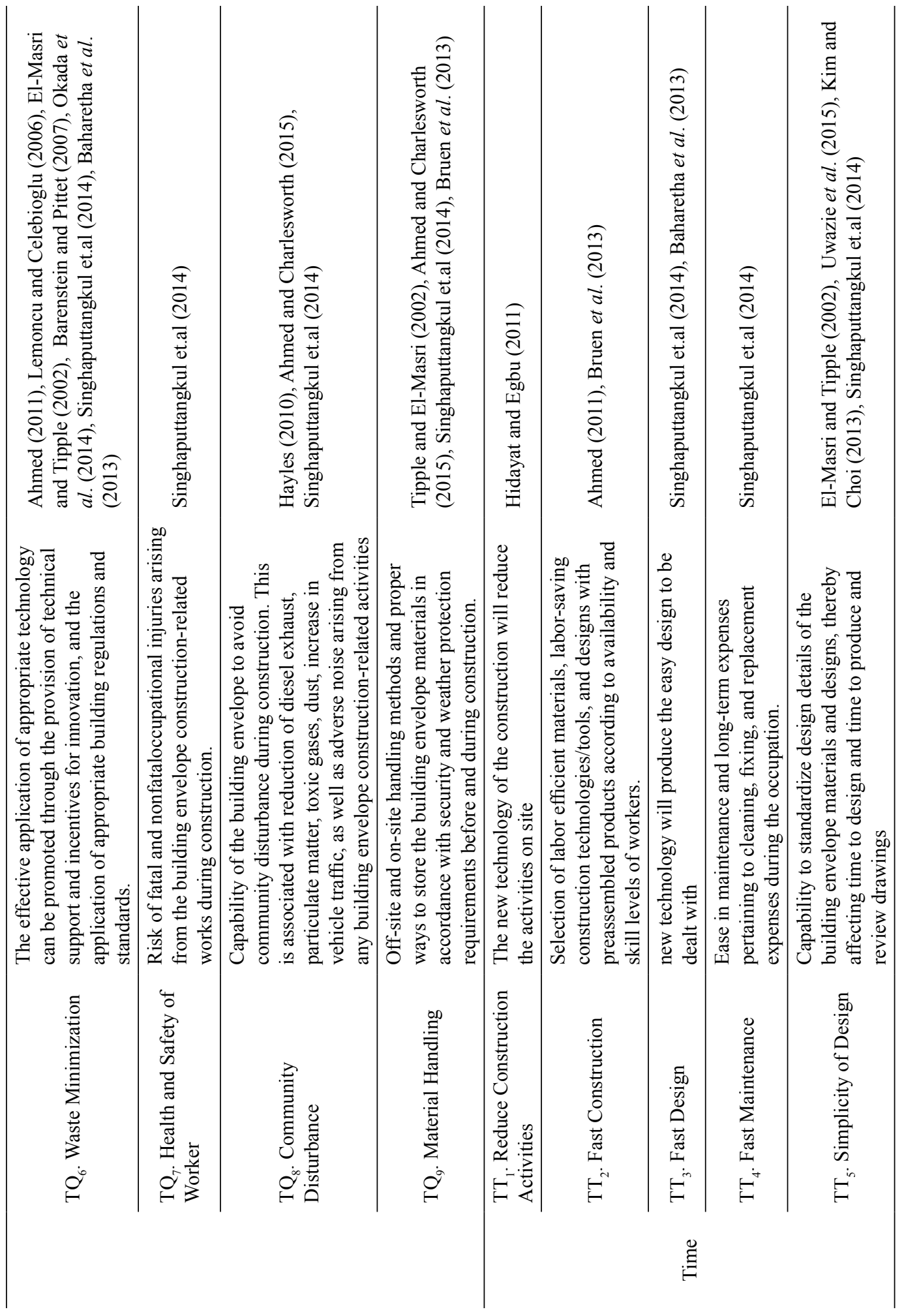




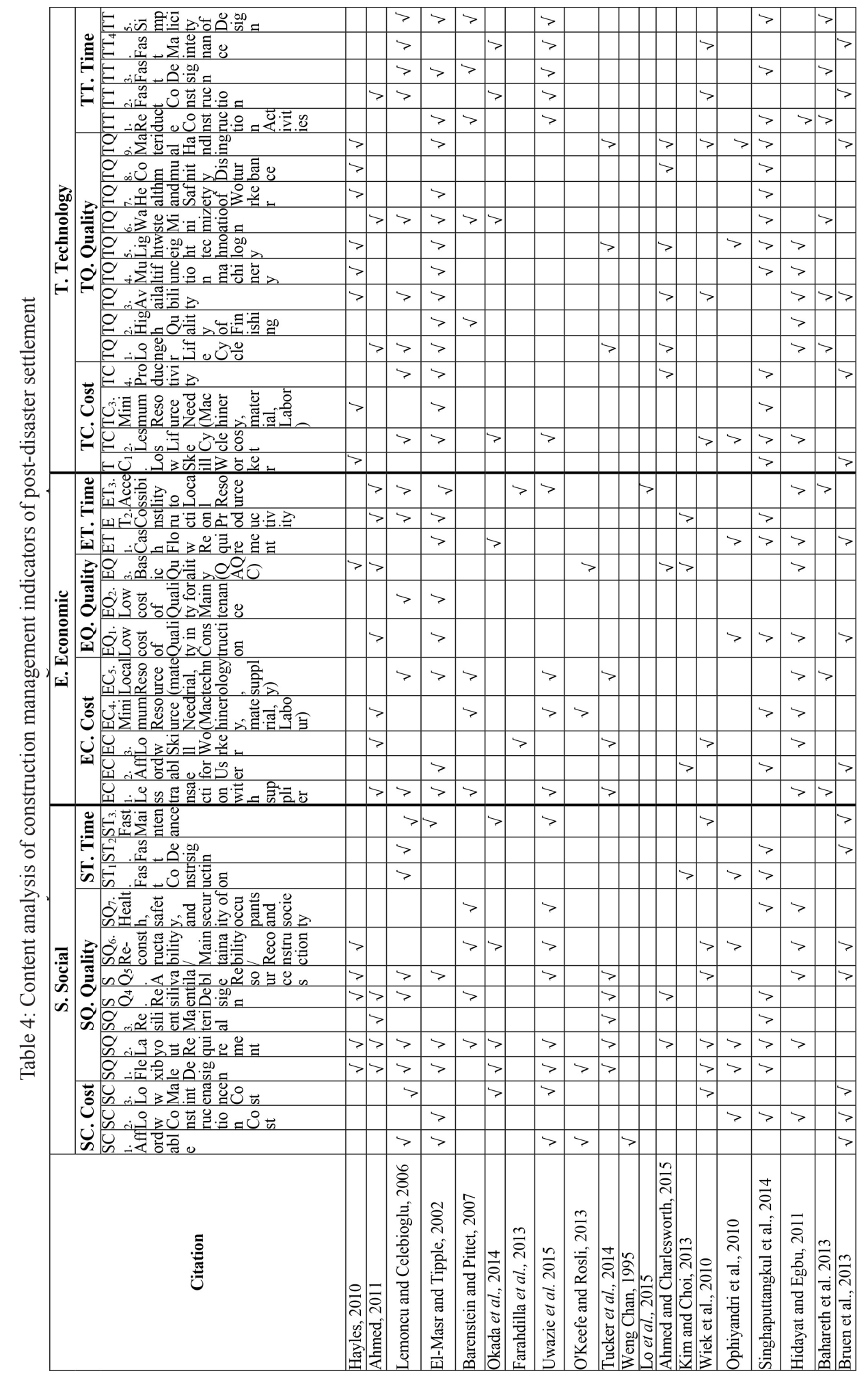


Applying the normalization (Equation 1) has determined the normalized weight (X) of all indicators (see Table 5). To calculate the actual normalized weight (AX), the normalized weight (X) was multiplied to the Sub-cluster Average. The following presents the normalization calculation for indicator $S C_{1}$ Affordable, as an example.

\section{Example;}

Indicator: $S C_{1}$ Affordable

Depth of Citation $(\mathrm{DoC})=6$

Sub-cluster Average $=0.30$

$X_{S C 1}=\frac{X_{i}-X_{\min }}{X_{\max }-X_{\min }}=\frac{6-2}{11}=0.36$

$A X_{S C 1}=0.36 \times 0.30=0.110$

Referring to Table 5, by completing the normalization process, the value of one indicator (i.e., $\mathrm{EQ}_{2}$ Low cost of Quality for Maintenance) has led to zero. Hence, the constant values of the indicator equaled zero. Therefore, the indicator may miss the index equation. Indeed, the inconsistent values could make data uncertain and ambiguous to interpret the index equation. As the normalization may make data go missing, the researchers had to handle it properly (Batista and Monard, 2003). The missing data may lead to errors, bias, or loss of efficiency in the assessment of the post-disaster settlement (Marler and Arora, 2010; Gelman and Hill, 2007). To handle the missing data of the indicator $\mathrm{EQ}_{2}$, we had to fill the data through the Single Imputation techniques, in particular, through the Attribute Mean Imputation method. This imputation technique is to complete the data matrix. It is to substitute and replace the missing data with a value based on the other information (here, the normalization data). The mean imputation retains such indicators removed from the data set (Howell, 2008). The mean imputation gives value to these criteria with the missing data since all of the criteria should be in the index model.

Figure 3 shows the cumulative Actual Normalized Weight of clusters (i.e., social, economic, technology) based on sub-clusters (i.e., cost, quality, time). As can be seen, the social cluster mainly contributes to post-disaster settlement compared to other clusters $\left(\mathrm{AX}_{\mathrm{S}} \mathrm{Sum}\right.$ $=2.298$ ), significantly, its quality-associated indicators are very supportive $\left(\mathrm{AX}_{\mathrm{SQ}}=0.52\right)$. Notably, the time- associated indicators of the economic cluster are more critical than other clusters $\left(\mathrm{AX}_{\mathrm{ET}}=0.39\right)$. Hence, these indicators should be primarily considered in the postdisaster settlement.

The SPS Assessment Model (see Equation 4) was formulated by transferring the Normalized Weight Average values of the subclusters, and Actual Normalized Weights (AX) of the indicators from Table 5 .

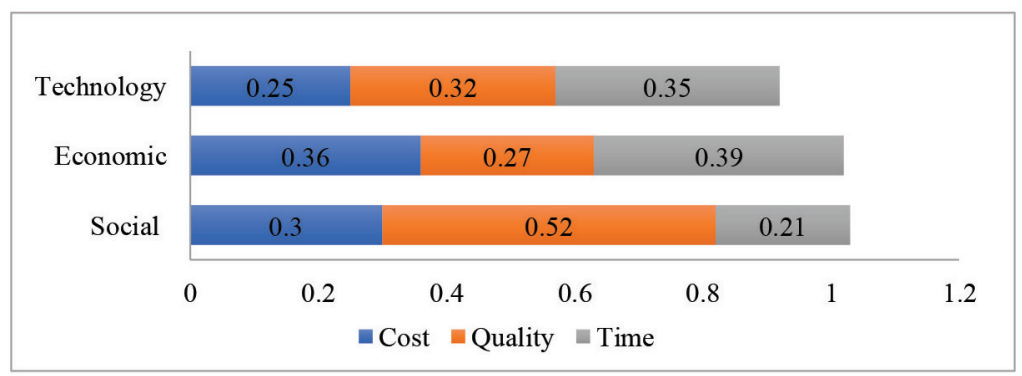

Figure 3: Actual Cumulative Normalized Weight of clusters based on sub-clusters 


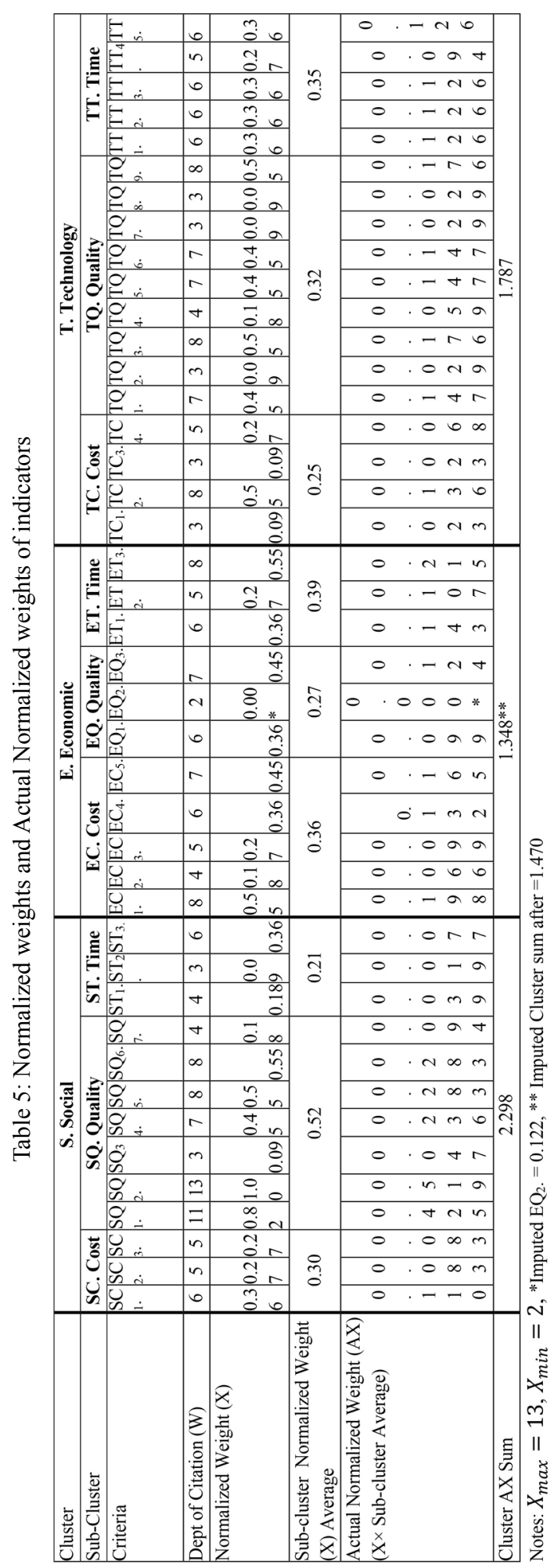


Sustainable Post-Disaster Settlement (SPS) Index $=$ SPS Index ${ }_{\text {Social }}+$ SPS Index $_{\text {Economic }}+$ SPS Index ${ }_{\text {Technology }}$

SPS Index $\mathrm{Social}=\sum 0.30\left(\mathrm{~N}_{\mathrm{SCi}} \mathrm{X}_{\mathrm{SCi}}\right)+\sum 0.52\left(\mathrm{~N}_{\mathrm{SQi}} \mathrm{X}_{\mathrm{SQi}}\right)+\sum 0.21\left(\mathrm{~N}_{\mathrm{STi}_{\mathrm{STi}}} \mathrm{X}_{\mathrm{ST}}\right)$

SPS Index ${ }_{\text {Economic }}=\sum 0.36\left(\mathrm{~N}_{\mathrm{ECi}} \mathrm{X}_{\mathrm{ECi}}\right)+\sum 0.27\left(\mathrm{~N}_{\mathrm{EQi}} \mathrm{X}_{\mathrm{EQi}}\right)+\sum 0.39\left(\mathrm{~N}_{\mathrm{ETi}} \mathrm{X}_{\mathrm{ETi}}\right)$

SPS Index ${ }_{\text {Technology }}=\sum 0.25\left(\mathrm{~N}_{\mathrm{TCi}} \mathrm{X}_{\mathrm{TCi}}\right)+\sum 0.32\left(\mathrm{~N}_{\mathrm{TQi}} \mathrm{X}_{\mathrm{TQi}}\right)+\sum 0.35\left(\mathrm{~N}_{\mathrm{TTi}} \mathrm{X}_{\mathrm{TTi}}\right)$

(Equation 4)

where,

$N_{S c i}, N_{S Q i}, N_{S T i}$; the consistent value for indicator ' $i$ ' in Social cluster, respectively, in Cost, Quality, and Time sub-clusters

$N_{E c i} N_{E Q i}, N_{E T i}$; the consistent value for indicator ' $i$ ' in Economic cluster, respectively, in Cost, Quality, and Time sub-clusters

$N_{T C i} N_{T Q i} N_{T T ;}$; the consistent value for indicator ' $i$ ' in Technology cluster, respectively, in Cost, Quality, and Time sub-clusters

$X_{S C i} X_{S Q i}, X_{S T i}$; the weight is assigned by experts during case assessment for indicator ' $i$ ' in Social cluster, respectively, in Cost, Quality, and Time sub-clusters

$X_{E C i}, X_{E Q i}, X_{E T i}$; the weight is assigned by experts during case assessment for indicator ' $i$ ' in Economic cluster, respectively, in Cost, Quality, and Time sub-clusters

$X_{T C i} X_{T Q i}, X_{T T i}$, the weight is assigned by experts during case assessment for indicator ' $i$ ' in T cluster, respectively, in Cost, Quality, and Time sub-clusters

The model users can insert the case assessment data to Equation 4 to evaluate the construction management performance of their post-flood settlement. The below presents the extended SPS Index social. Transferring the Actual Normalized Weights (AX) of the socialassociated indicators from Table 5 generates the Equation 5. The same can be done for the economic and technology clusters. As can be seen in Equation 5, each indicator has a consistent value multiplied to the weight values of $\mathrm{X}_{\mathrm{SCi}}, \mathrm{X}_{\mathrm{SQi}}, \mathrm{X}_{\mathrm{STi}}$. The weight values of $\mathrm{X}_{\mathrm{SCi}}$, $\mathrm{X}_{\mathrm{SQi}}, \mathrm{X}_{\mathrm{STi}}$ should be assigned by the model-user during their case assessment (through field survey or interviews) using a 5-point scale (where one refers to poor to five refers to very good).
The SPS Assessment Model defines four grades based on the index scores; Gold, Silver, Bronze, and Not certified. The SPS Index ${ }_{\text {Max }}$ was calculated by assuming value one as the maximum possible value to all indicators. By assigning value one to all indicators in Equation 4, the SPS Index ${ }_{\text {Max }}$ equaled to 5.555. And, of course, by assigning value zero to all indicators, the SPS Index ${ }_{\text {Min }}$ equaled to 0.000 . Referring to the below grades, the Gold grade refers to the best grade when the indexing score is between 5.001 and 5.555, while the Bronze grade refers to the lowest grade when the indexing score is between 1.001 and 3.000. A score of less than 1.000 is a fail.

The extended SPS Index ${ }_{\text {Social }}$;

SPS Index $_{\text {Social }}=\sum 0.30\left[\left(0.110 X_{S C 1}+0.083 X_{S C 2}+0.083 X_{S C 3}\right)\right]+\sum 0.52\left[\left(0.0425 X_{S Q 1}+0.519 X_{S Q 2}+0\right.\right.$ $\left.\left..047 X_{S Q 3}+0.0236 X_{S Q 4}+0.283 X_{S Q 5}+0.283 X_{S Q 6}+0.0948 X_{S Q}\right)\right]+\sum 0.21\left[\left(0.039 X_{S T 1}+0.019 X_{S T 2}+0.077\right.\right.$ $\left.\left.X_{S T 3}\right)\right]$

(Equation 5) 


SPS grading
scores (s): $\left\{\begin{array}{l}5.001 \leq \mathrm{s} \leq 5.555: \text { Gold: The social-economic-technical } \\ \text { performances of the construction management project have } \\ \text { significantly supported the post-flood disaster settlement. } \\ 3.001 \leq \mathrm{s}<5.000 \text { : Silver: The social-economic-technical } \\ \text { performances of the construction management project have } \\ \text { properly supported the post-flood disaster settlement. } \\ 1.001 \leq \mathrm{s}<3.000 \text { : Bronze: The social-economic-technical } \\ \text { performances of the construction management project have } \\ \text { fairly supported the post-flood disaster settlement. } \\ 0.000 \leq \mathrm{s}<1.000 \text { : Not certified. }\end{array}\right.$

\section{Validating the SPS Assessment Model}

Once a new model has been developed, it should be validated. The validation of the new model or analytical method is a testing process to determine and prove whether the model is feasible, capable, and useful for its intended purposes and conditions (Lavanya et al., 2013). The validation procedure can provide the researcher the quality-control and regulatory requirements of the advanced science through the quantitative tests. The validation indicates whether the model outputs are accurate, reproducible, reliable and valid. Hence, the validation can establish the specificity, sensitivity, and reproducibility of the model (Belouafa et al., 2017). Accordingly, this research has conducted a usability study to validate the SPS assessment model. The usability study can determine the closeness of model results to the valid values. The usability study evaluates technical and operational aspects to observe the impairment or deficiencies in using the model, if any. Scholtz (2006) and Seffah et al. (2006) state that the usability study by end-users aids in collecting their feedback and satisfaction on the interpretation of data. The usability study has the following nine factors: effectiveness, efficiency, productivity, learnability, satisfaction, accessibility, trustfulness, usefulness, and universality (Seffah et al., 2006).

The SPS assessment model was validated from two aspects; research goals (i.e., research concept, indicators, and clustering), and collecting and processing (i.e., the field survey and interview which are used for data collection, and SPS indexing which is used for data analysis). These aspects have been validated across nine usability factors. Table 6 presents the results of WSM for the usability validation of the SPS assessment model. The validation results show that the experts had an overall consensus on the model's usability since all usability factors have received the minimum saturation (i.e., 70 $\%$ saturation). According to Table 6 , the experts had $100 \%$ consensus on some of the usability factors (i.e., efficiency, learnability, accessibility, and universality) associated with research goals, as well as, effectiveness, productivity, accessibility, universality of the data collecting and processing. In some cases, the experts agreed with $93 \%$ and $86 \%$ saturation. Collectively, the research asserts that the SPS assessment model is valid sufficiently to be practically used. 
Table 6: Usability validation of the SPS assessment model

\begin{tabular}{|c|c|c|c|c|c|c|c|c|}
\hline Usability va & idation factors & $\begin{array}{l}\text { SPS Assessment } \\
\text { Model } \\
\text { Characteristics }\end{array}$ & $w_{1}$ & $w_{2}$ & $w_{3}$ & $\operatorname{WSM}\left(a_{i}\right)$ & $W S M(a)_{\max }$ & Consensus \\
\hline \multirow{9}{*}{$\begin{array}{l}\text { Usability } \\
\text { factors }\end{array}$} & Efficiency & \multirow{9}{*}{$\begin{array}{l}\text { Goals: } \\
\text { i. Research } \\
\text { Concept } \\
\text { ii. Criteria } \\
\text { iii. Clustering }\end{array}$} & 5 & 5 & 5 & 15 & 15 & 100 \\
\hline & Effectiveness & & 4 & 5 & 4 & 13 & 15 & 86 \\
\hline & Productivity & & 5 & 4 & 5 & 14 & 15 & 93 \\
\hline & Satisfaction & & 4 & 5 & 4 & 13 & 15 & 86 \\
\hline & Learnability & & 5 & 5 & 5 & 15 & 15 & 100 \\
\hline & Trustfulness & & 5 & 5 & 4 & 14 & 15 & 93 \\
\hline & Accessibility & & 5 & 5 & 5 & 15 & 15 & 100 \\
\hline & Universality & & 5 & 5 & 5 & 15 & 15 & 100 \\
\hline & Usefulness & & 4 & 5 & 4 & 13 & 15 & 86 \\
\hline \multirow{9}{*}{$\begin{array}{l}\text { Usability } \\
\text { factors }\end{array}$} & Efficiency & \multirow{9}{*}{$\begin{array}{l}\text { Data Collecting } \\
\text { and Processing: } \\
\text { i. Field survey } \\
\text { ii. Interview } \\
\text { survey } \\
\text { iii.Linear } \\
\text { index } \\
\text { formula }\end{array}$} & 5 & 4 & 5 & 14 & 15 & 93 \\
\hline & Effectiveness & & 5 & 5 & 5 & 15 & 15 & 100 \\
\hline & Productivity & & 5 & 5 & 5 & 15 & 15 & 100 \\
\hline & Satisfaction & & 5 & 5 & 4 & 14 & 15 & 93 \\
\hline & Learnability & & 4 & 5 & 4 & 13 & 15 & 86 \\
\hline & Trustfulness & & 5 & 5 & 4 & 14 & 15 & 93 \\
\hline & Accessibility & & 5 & 5 & 5 & 15 & 15 & 100 \\
\hline & Universality & & 5 & 5 & 5 & 15 & 15 & 100 \\
\hline & Usefulness & & 4 & 5 & 4 & 13 & 15 & 86 \\
\hline
\end{tabular}

Note: Consensus is calculated through Equation 3.

\section{Discussion}

Governments are often required to tackle disasters by increasing their capacity and knowledge in construction management and technologies that are sustainable, green and trustable. The primary issue of post-disaster construction is usually defined as re-building the physical environment by emphasizing on housing in the recovery programs (Keyvanfar et al., 2014). Hence, post-disaster construction and immediate housing have become the primary target for local authorities, construction managers, civil engineers, and communities.

Disaster management models mostly focus on disaster issues through mitigation, prevention, response, and recovery; however, these models are not able to cover all dimensions of disaster management, and have some limitations. For example, the integrated models comprise most of the disaster management plans and activities, and response to recovery activities, not specified activities. Or, the logical models establish the conceptual frameworks for only primary disaster management actions and cannot conduct risk management and hazard assessment. Hence they cannot describe beyond these stages. Moreover, the causal models focus only on unsafe conditions and identify just the core pressure and root causes of a disaster. his research resolves these shortcomings by establishing a sustainable disaster assessment model focusing on postdisaster settlement after flooding, called the SPS assessment model. As flood disaster destroys the functions of the community's buildings and transportation infrastructure for a short and long period, the SPS assessment model has been developed based on two approaches; socioeconomic resilience (i.e., maintaining the system structure, function, and transition management), 
and technical infrastructure resilience (i.e., system response and recovery).

\section{Theoretical Implications of Findings}

The decision theories have an outcome-based and data-driven approach, and the administrative theories have a process-based approach, while both of the theories are primarily tacticalfocused types of theories (Sementelli, 2007). The SPS assessment model has presented a new approach to sustainable disaster management for post-disaster responses. Sustainable advancement was made in the realm of postdisaster theorizing and development. Applying the SPS assessment model aids in understanding the cost-quality-time risk control across sustainability dimensions (social, economic and technology aspects), which is supported by decision-making theories and administrative theories.

The SPS assessment model has applied the decision-making theory to frame the disaster theories from different contexts; information access, data quality and perception. Sementelli (2007) states that the decision-making theory is consistent; however, disaster management is an interdisciplinary field of research and still developing. Sementelli (2007) and Mille (2002) state that the decision theories of disaster management science are lacking from some aspects, which is seen in policy studies. The decision theories have a reliance on hyper-rational structures, top-down approach, production-line models, and process-based concerns. Sementelli (2007) states that the decision theories are such order-based rational models and somewhat encompassing the context, issues, and contents of disasters. In this regard, the SPS assessment model has followed the basics of administrative theories of disaster, which needs to respond and rebuild in a timely way; in particular, coordination among structures, personnel, emergency responders in the context of decentralization of construction management. Kapucu and Garayev (2011), and Voogd (2004) state that administrative theories have some limitations in command and control- based disaster prevention systems; however, the decentralization can recover it through an integral process. Smits and Ally (2003) state that integrating the management team's discussion through an assessment process is a practical mechanism to support the administrative theories. On this basis, the SPS assessment model provides a decision-making platform for all managerial and organizational levels involved in the disaster settlement project. Hence, the SPS assessment model focuses significantly on managerial and administrative aspects through performance measures, output control, stringent control over resources, and decentralization. These notions of streamlined managerial operations have a certain tacit appeal, especially when recovery efforts become obstacles and negative forces.

Moreover, the primary motivation of advances in disaster theories was on integrating potential linkages among disaster management constructs, mainly, by adapting decision-making science and policy-making and demonstrating the idea of vulnerability management (Smits and Ally, 2003; Kouzmin, 2007). In this regard, scholars have consistently expressed the need for a common language, recognition of the multidimensional nature of disaster management (i.e., physical, social, economic, and political aspects) (McEntire and Fuller, 2002). The current research has significant implications for disaster and administrative theories, particularly in decentralizing the structure and nature of the post-disaster management system. Indeed, any effort to guarantee the quality and risk control after disaster management must be in support of the decision-maker network. For instance, the SPS model highlights the flexible design, which was not included in prior post-disaster management models. Furthermore, governing post-disaster interventions can be better guided by local authorities, NGOs (non-governmental organizations), and engineers, which are the central disaster management agencies, that often are not able to comprehend the complexity of a crisis. Using the SPS model enables these parties to convert and transform their experiences into the list of lessons-learned and best-practices. 
Meanwhile, using the SPS model provides opportunities for respective model-users (i.e., construction managers, civil engineers, local authorities, etc.) to play coordination roles more effectively.

\section{Practical Implications of Findings}

Construction management professionals are trying to inspire the country-based perspectives of post-disaster management to a more consistent and detailed global-based perspective. In this regard, the researchers in different disciplines (construction management, civil engineering, urban development, transportation, and public health) are attempting to tease out the inconsistency and inherency of existing countrybased post-disaster management models, and develop a holistic solution. Thus, the SPS model was pursued to merge the decisionmaking theories and administrative theories into a unique system. The SPS model, as a universal decision support tool, can aid civil and construction professionals for either ongoing or future disaster management projects.

In particular, the SPS assessment model aids construction and civil professionals to control the negative consequences of flood disasters. It mainly helps to evaluate the social, economic, and technology dimensions of sustainable construction management in the post-disaster management projects. The analysis results of the SPS model can determine the strengths and weaknesses of the construction management system in handling post-disasters. Accordingly, construction professionals can make the most suitable recovery decisions and plans for their flooded communities. The SPS assessment model is highly recommended for construction professionals, especially in tropical regions. The model was developed based on a robust theoretical and conceptual framework, covering 42 key drivers for post-disaster settlement. The model was developed based on a tight methodology to measure weights of these indicators while designing an uncomplicated simplistic procedure for data collection and data processing; so, the SPS model offers exceptional capacities in quick response at severe time constraints. The SPS model collects first-hand data through field surveys and interviews with experts, hence, it makes a common and understandable basis for all users, either professionals, practitioners, or community members. Besides, the SPS assessment model is such a universal and logical disaster assessment model (like Kimberly model and Tuscaloosa model); hence, it has uncomplicated disaster management stages through standardized and systematic approaches.

\section{Conclusion}

The research highlights an essential need for evaluating the construction management capacities in post-disaster management principally after floods. To address the need, this research developed a novel tool called Sustainable Post-disaster Settlement (SPS) assessment model, which can evaluate and quantify the construction management performance and capabilities on post-disaster settlement of flooding. Notably, the SPS assessment model evaluates the performance of construction management projects across human resources, financial resources, and machinery technologies, as well as, time, cost, and quality dimensions. The SPS model is such a universal multi-criteria decision-making tool and a logical model that covers 42 construction management indicators. The conceptual framework of the SPS assessment model has abstracted the complicated assessment procedure of post-disaster settlement into a simple index formula. Therefore, the model users (e.g., construction managers, developers, civil engineers, and contractors) all around the world can use it to control the negative consequences of flood disasters quickly and efficiently. By implementing the model to the real cases, the construction professionals can recognize the strengths and weaknesses of their post-disaster construction practices. Accordingly, construction professionals can make the most suitable recovery and settlement plans for the flooded community and areas. 
The research faced several limitations regarding the model's construct, calibration and implementation that can be resolved in future research. In particular, we need to shift our thinking mainly to sustainable postdisaster reconstruction. The SPS model has focused on the construction phase of postdisaster settlement; however, the architectural or structural phases could be covered as well. Besides, post-disaster management did not fit neatly into the disaster management mainstream. Hence, post-disaster management needs to be improved through taking advantage of other theories and concepts (such as sustainability concept, Gramscian or Foucault social theories); otherwise, it remains in its infancy. So, there is room to continue and extend this research in the future to enhance the SPS model's usability, feasibility, and serviceability. The SPS model is rich in theoretical backgrounds and qualitative assessment, but it cannot conduct the quantitative assessment like computable equilibrium models. Merging the SPS model with other MCDM methods, Fuzzy methods, or GIS-based methodology would promote its accuracy of evaluation and assessment. Significantly, the Fuzzy methodology can integrate data and scales, and can measure the qualitative data precisely; therefore, the outputs will reflect uncertainty and exactitude. Also, the research sought to calibrate the criteria and validate the model to extend empirical data. The complexity of the SPS model suggests advanced computing methods for further calibration and normalization. For instance, generic algorithms and artificial neural networks would be the appropriate methods to this end. Also, the SPS model can be integrated to ArcGIS to facilitate the actual and real-time spatial data analysis in different scales (i.e., regional, city, district, or neighborhood) for visualization of the outputs, settlement dynamic spatial data, modeling household recovery, and querying the numbers of recovered houses after flood. Finally, the SPS assessment model can be promoted to standalone or web-based software in the future, which may make it more accessible and applicable globally.

\section{Acknowledgements}

The authors extend their gratitude to reviewers for critical comments on the manuscript.

\section{References}

AAhmed, I. (2011). An overview of postdisaster permanent housing reconstruction in developing countries. International Journal of Disaster Resilience in the Built Environment, 2(2), 148-164.

Ahmed, I., \& Charlesworth, E. R. (2015). An evaluation framework for assessing resilience of post-disaster housing. International Journal of Disaster Resilience in the Built Environment, 6(3), 300-312.

Allison, G. T., \& Zelikow, P. (1971). Essence of decision: Explaining the Cuban missile crisis (Vol. 327, No. 729.1). Boston: Little, Brown.

Anand, P., \& Forshner, C. (1995). Of mad cows and marmosets: From rational choice to organizational behaviour in crisis management. British Journal of Management, 6(4), 221-233.

Arbon, P., Gebbie, K., Cusack, L., Perera, S., \& Verdonk, S. (2012). Developing a model and tool to measure community disaster resilience. Torrens Resilience Institute, 28.

Asghar, S., Alahakoon, D., \& Churilov, L. (2006). A comprehensive conceptual model for disaster management. Journal of Humanitarian Assistance, 1360(0222), $1-15$.

Baharetha, S. M., Al-Hammad, A. A., \& Alshuwaikhat, H. M. (2013). Towards a Unified Set of Sustainable Building Materials Criteria. In ICSDEC 2012@ Developing the Frontier of Sustainable Design, Engineering, and Construction. 732-740).

Barenstein, J. D., \& Pittet, D. (2007). Postdisaster housing reconstruction: Current trends and sustainable alternatives 
for tsunami-affected communities in coastal Tamil Nadu. Institute for Applied Sustainability to the Built Environment, University of Applied Sciences of Southern Switzerland, Canobbio.

Barnett, D. J., Balicer, R. D., Blodgett, D. W., Everly Jr, G. S., Omer, S. B., Parker, C. L., \& Links, J. M. (2005). Applying risk perception theory to public health workforce preparedness training. Journal of Public Health Management and Practice, 11(6), S33-S37.

Batista, G. E. A. P. A., \& Monard, M. C. (2003). An analysis of four missing data treatment methods for supervised learning. Applied Artificial Intelligence, 17(5), 519-533.

Belouafa, S., Habti, F., Benhar, S., Belafkih, B., Tayane, S., Hamdouch, S., ... \& Abourriche, A. (2017). Statistical tools and approaches to validate analytical methods: Methodology and practical examples. International Journal of Metrology and Quality Engineering, 8, 9.

Borecký, J., Kohlík, M., \& Kubátová, H. (2016). Parity Waterfall Method. In 2016 IEEE 19th International Symposium on Design and Diagnostics of Electronic Circuits \& Systems (DDECS) (pp. 1-6). IEEE.

Brown, D., Saito, K., Spence, R., Chenvidyakarn, T., Adams, B., Mcmillan, A., \& Platt, S. (2008). Indicators for measuring, monitoring and evaluating post-disaster recovery. In Proceedings 6th International Workshop on Remote Sensing for Disaster Applications, Pavia, Italy.

Bruen, J., Hadjri, K., \& von Meding, J. (2013). Design drivers for affordable and sustainable housing in developing countries. Journal of Civil Engineering and Architecture, 7(10), 1220-1228.

Coetzee, C., \& Van Niekerk, D. (2012). Tracking the evolution of the disaster management cycle: A general system theory approach. Jàmbá: Journal of Disaster Risk Studies, 4(1), 1-9.
Cohen, M. D., March, J. G., \& Olsen, J. P. (1972). A garbage can model of organizational choice. Administrative Science Quarterly, $1-25$.

Connor, J. A. (2009). Pascal's wager: The man who played dice with God. Harper Collins.

De Bruijn, K. M. (2004). Resilience indicators for flood risk management systems of lowland rivers. International Journal of River Basin Management, 2(3), 199-210.

El-Masri, S., Tipple, G. (2002). Natural disaster, mitigation and sustainability: The case of developing countries. International Planning Studies, 7(2), 157-175.

Fairholm, M. R. (2004). Different perspectives on the practice of leadership. Public Administration Review, 64(5), 577-590.

Farahdilla, C. E., Mansur, S. A., \& Abdullah, A. (2013). Common issues in post-disaster reconstruction. Malaysian Journal of Civil Engineering, 25(2).

Geale, S. K. (2012). The ethics of disaster management. Disaster Prevention and Management: An International Journal.

Gelman, A., \& Hill, J. (2007). Data analysis using regression and multilevel/hierarchical models. New York, NY: Cambridge University Press.

Ghamghami, M., \& Irannejad, P. (2019). An analysis of droughts in Iran during 19882017. SN Applied Sciences, 1(10), 1217.

Gotham, K. F. (2007). Critical theory and Katrina: Disaster, spectacle and immanent critique. City, 11(1), 81-99.

Gourbesville, P. (2012). Urban flooding and Resilience: Concepts and needs. EGU General Assembly Conference, 14, 14282.

Guikema, S. D. (2009). Natural disaster risk analysis for critical infrastructure systems: An approach based on statistical learning theory. Reliability Engineering \& System Safety, 94(4), 855-860. 
Hayles, C. S. (2010). An examination of decision making in post disaster housing reconstruction. International Journal of Disaster Resilience in the Built Environment, 1(1), 103-122.

Heijmans A. (2001). Vulnerability: A Matter of Perception, Disaster Management Working Paper 4/2001, Benfield Greig Hazard Research Centre University College of London.

Hidayat, B., \& Egbu, C. (2011, September). Critical Success Factors Associated With Post-Disaster Reconstruction Projects. In Procs 27th Annual ARCOM Conference, 5-7 September 2011 (pp. 889-898). Association of Researchers in Construction Management. Bristol, UK.

Howell, D. C. (2008). The treatment of missing data. In W. Outhwaite \& S. Turner (Eds.), Handbook of Social Science Methodology. London: Sage. Retrieved April 26, 2013, from http://www.uvm.edu/ dhowell/ StatPages/More_Stuff/Missing_Data/ MissingDataFinal.pdf.

Ibrahim M. S., Fakharu'l-razi A., \& Aini M. S. (2003). A review of disaster and crisis. Disaster Prevention and Management, 12(1), 24-32.

Kapucu, N., \& Garayev, V. (2011). Collaborative decision-making in emergency and disaster management. International Journal of Public Administration, 34(6), 366-375.

Keller A. Z., \& Al-madhari A. F. (1996). Risk management and disasters. Disaster Prevention and Management, 5(5), 19-22.

Kelly C. (1998). Simplifying disasters: Developing a model for Complex Nonlinear Events. Proceedings of International Conference on Disaster Management: Crisis and Opportunity: Hazard Management and Disaster Preparedness in Australasia and the Pacific Region, Cairns, Queensland, Australia, pp. 25-28, 1-4 November, 1998.

Keyvanfar, A., Khorami, M., González Moya, C., Cruz Cabrera, M., Revelo Báez, C.
N., \& Estupiñán, M. (2018). Rethinking construction corporate social responsibility practices: Construction neighborhood. IIOAB Journal, 9(3), 9-13.

Keyvanfar, A., Shafaghat, A., Majid, M. Z. A., Lamit, H., \& Ali, K. N. (2014). Correlation study on user satisfaction from adaptive behavior and energy consumption in office buildings. Jurnal Teknologi, 70(7).

Kimberly, A. (2003). Disaster preparedness in Virginia Hospital Center-Arlington after Sept 11, 2001. Disaster Management and Response, 1(3), 80-86.

Kou, G., Ergu, D., \& Shi, Y. (2014). An integrated expert system for fast disaster assessment. Computers \& Operations Research, 42, 95-107.

Kouzmin, A., \& Jarman, A. M. (2004). Policy advice as crisis: A political redefinition of crisis management. International Studies Review, 6(1), 182-194.

Lamit, H., Shafaghat, A., Majid, M. Z., Keyvanfar, A., Ahmad, M. H. B., \& Malik, T. A. (2013). Grounded Group Decision Making (GGDM) Model. Advanced Science Letters, 19(10), 3077-3080.

Lassa, J. A. (2012). Post disaster governance, complexity and network theory: Evidence from Aceh, Indonesia after the Indian Ocean Tsunami 2004. PLoS currents, 7.

Lavanya, G., Sunil, M., Eswarudu, M. M., Eswaraiah, M. C., Harisudha, K., \& Spandana, B. N. (2013). Analytical method validation: An updated review. International Journal of Pharmaceutical Sciences and Research, 4(4), 1280.

Levy, J. K., Gopalakrishnan, C., \& Lin, Z. (2005). Advances in decision support systems for flood disaster management: Challenges and opportunities. Water Resources Development, 21(4), 593-612.

Lin, Z., Zhao, X., Ismail, K. M., \& Carley, K. M. (2006). Organizational design and restructuring in response to crises: Lessons from computational modeling and real- 
world cases. Organization Science, 17(5), 598-618.

Liu, W., \& Li, W. (2009). To determine the weight in a weighted sum method for domainSpecific keyword extraction. In 2009 International Conference on Computer Engineering and Technology (Vol. 1, pp. 11-15). IEEE.

Marcus, O. (2005). A Conceptual Framework for Risk Reduction. World Conference of Disaster Reduction, Kobe, Japan, 18-22 January 2005.

Marler, R. T., \& J. S. Arora. (2010). The Weighted Sum Method for Multi-objective Optimization: New insights. Structural and Multidisciplinary Optimization, 41(6), 853862.10.1007/s00158-009-0460-7

Mayring, P. (2003). Qualitative Inhaltanalyse - Grundlagen und Techniken (Qualitative Content Analysis - Basics and Techniques) (8th ed.). Beltz Verlag, Weinheim.

McEntire, D. A., \& Fuller, C. (2002). The need for a holistic theoretical approach: an examination from the El Niño disasters in Peru. Disaster Prevention and Management: An International Journal.

Mingers, J. (2003). The paucity of multimethod research: A review of the information systems literature. Information Systems Journal, 13(3), 233-249.

Mohd, M. H., Azman, F. N. U. Z., Jusoh, A., \& Rahman, M. A. A. (2019). Landslide susceptibility mapping at Lebir and Galas River Basins after extreme flood event using weights of evidence. Journal of Sustainability Science and Management, 14(2), 103-115.

Norris, F. H., Stevens, S. P., Pfefferbaum, B., Wyche, K. F., \& Pfefferbaum, R. L. (2008). Community resilience as a metaphor, theory, set of capacities, and strategy for disaster readiness. American Journal of Community Psychology, 41(1-2), 127-150.

Okada, T., Haynes, K., Bird, D., van den Honert, R., \& King, D. (2014). Recovery and resettlement following the 2011 flash flooding in the Lockyer Valley. International Journal of Disaster Risk Reduction, 8, 2031.

Ophiyandri, T., Amaratunga, R. D. G., \& Pathirage, C. P. (2010). Community based post disaster housing reconstruction: Indonesian perspective.

O'sullivan, T. L., Kuziemsky, C. E., ToalSullivan, D., \& Corneil, W. (2013). Unraveling the complexities of disaster management: A framework for critical social infrastructure to promote population health and resilience. Social Science \& Medicine, 93, 238-246.

Robinson, M. D., \& Oshlack, A. (2010). A scaling normalization method for differential expression analysis of RNA-seq data. Genome Biology, 11(3), R25.

Rubin, C. B. (1985). The community recovery process in the United States after a major natural disaster. International Journal of Mass Emergencies and Disasters, 3, 9-28.

Saunders, M. N., \& Rojon, C. (2011). On the attributes of a critical literature review. Coaching: An International Journal of Theory, Research and Practice, 4(2), 156-162.

Scholtz, J. (2006). Beyond usability: Evaluation aspects of visual analytic environments. In 2006 IEEE Symposium on Visual Analytics Science and Technology (pp. 145-150). IEEE.

Seffah, A., Donyaee, M., Kline, R. B., \& Padda, H. K. (2006). Usability measurement and metrics: A consolidated model. Software Quality Journal, 14(2), 159-178.

Sementelli, A. (2007). Toward a taxonomy of disaster and crisis theories. Administrative Theory \& Praxis, 29(4), 497-512.

Shafaghat, A., Keyvanfar, A., Lamit, H., Mousavi, S. A., \& Majid, M. Z. A. (2014). Open plan office design features affecting staff's health and well-being status. Jurnal Teknologi, 70(7). 
Shafaghat, A., Keyvanfar, A., Manteghi, G., \& Lamit, H. B. (2016b). Environmentalconscious factors affecting street microclimate and individuals' respiratory health in tropical coastal cities. Sustainable Cities and Society, 21, 35-50.

Shafaghat, A., Manteghi, G., Keyvanfar, A., Lamit, H. B., Saito, K., \& Ossen, D. R. (2016a). Street geometry factors influence urban microclimate in tropical coastal cities: A review. Environmental and Climate Technologies, 17(1), 61-75.

Singhaputtangkul, N., Low, S. P., Teo, A. L., \& Hwang, B. G. (2013). Criteria for architects and engineers to achieve sustainability and buildability in building envelope designs. Journal of Management in Engineering, 30(2), 236-245.

Smits, S. J., \& Ally, N. E. (2003). “Thinking the unthinkable"-Leadership's role in creating behavioral readiness for crisis management. Competitiveness Review: An International Business Journal.

Surwase, T., Manjusree, P., Nagamani, P. V., \& Jaisankar, G. (2019). Novel technique for developing flood hazard map by using AHP: A study on part of Mahanadi River in Odisha. SN Applied Sciences, 1(10), 1196.

Tsai, C. H., \& Chen, C. W. (2011). The establishment of a rapid natural disaster risk assessment model for the tourism industry. Tourism Management, 32(1), 158171.

Tucker, S., Gamage, A., Wijeyesekera, C. (2014). Some design aspects of sustainable post-disaster housing. International Journal of Disaster Resilience in the Built Environment, 5(2), 163-181.

Tyler, M. B., O’Prey, K., \& Kristiansson, K. (2002). Redevelopment after earthquakes. Portola Valley, CA: Spangle Associates.

Ubaura, M., Nieda, J., \& Miyakawa, M. (2016). Building reconstruction after Large-Scale Disasters A case study of
Ishinomaki City after the Great East Japan Earthquake. Journal of Disaster Research, 11, 780-788.

United Nations. (2012). World Urbanization Prospects, The 2011 Revision - Highlights, New York.

Uwazie, I., Igwemma, A. A., Osmond N. Okonkwo. (2015). Sustainable development in the Nigerian Housing Sector: Challenges and opportunities of achieving the Green Initiative, International Journal of African and Asian Studies, 12.

Vecere, A., Monteiro, R., Ammann, W. J., Giovinazzi, S., \& Santos, R. H. M. (2017). Predictive models for post disaster shelter needs assessment. International Journal of Disaster Risk Reduction, 21, 44-62.

Voogd, H. (2004). Disaster prevention in urban environments. European Journal of Spatial Development, 12, 1-14.

Weichselgartner J. (2001), Disaster mitigation: The concept of vulnerability revisited. Disaster Prevention and Management, 10(2), 85-94.

Weng Chan, N. (1995). Flood disaster management in Malaysia: an evaluation of the effectiveness of government resettlement schemes. Disaster Prevention and Management: An International Journal, 4(4), 22-29.

Wiek, A., Ries, R., Thabrew, L., Brundiers, K., Wickramasinghe, A. (2010). Challenges of sustainable recovery processes in tsunami affected communities. Disaster Prevention and Management: An International Journal, 19(4), 423-437.

Zhao, J., Jin, J., Guo, Q., Liu, L., Chen, Y., \& Pan, M. (2014). Dynamic risk assessment model for flood disaster on a projection pursuit cluster and its application. Stochastic Environmental Research and Risk Assessment, 28(8), 2175-2183. 